\title{
Preparation for becoming members of health care teams: findings from a 5-year evaluation of a student interprofessional training ward
}

\author{
Staffan Pelling, Anders Kalén, Mats Hammar and Ola Wahlström
}

\section{Linköping University Post Print}

N.B.: When citing this work, cite the original article.

Original Publication:

Staffan Pelling, Anders Kalén, Mats Hammar and Ola Wahlström, Preparation for becoming members of health care teams: findings from a 5-year evaluation of a student interprofessional training ward, 2011, Journal of Interprofessional Care, (25), 5, 328-332.

http://dx.doi.org/10.3109/13561820.2011.578222

Copyright: Informa Healthcare http://informahealthcare.com/

Postprint available at: Linköping University Electronic Press

http://urn.kb.se/resolve?urn=urn:nbn:se:liu:diva-70216 
Version för parallellpublicering : Journal of Interprofessional Care, 2011, 25: 328-332.

Pelling S, Kalen A, Hammar M, Wahlström O. Preparation for becoming members of health care teams: findings from a 5-year evaluation of a student interprofessional training ward. Journal of Interprofessional Care, 2011, 25: 328-332.

\section{Preparation for becoming part of future health- care teams; findings from} a 5-year evaluation of a student interprofessional training ward.

\section{Introduction:}

Todays management of health care problems is dependant on team work. Cooperation between professionals from different areas of health care is a prerequisite for successful everyday clinical work, whether in primary health care centres or in a super-specialized hospital setting. Knowledge about the respective skills, competence and roles of other professionals enables the optimal use of individual competencies and of the team as a whole. An increasing amount of reports on interprofessional learning and practice points to the importance of teamwork in health care (Baxter \& Brumfitt, 2008; Berlin \& Carlström, 2008; Burke, Salas, Wilson-Donnelly, \& Priest, 2004; Harris et al., 2010; Lupton \& Khan, 1998; Oandasan \& Reeves 2005; Patel, Pratt, \& Patel, 2008; Pronovost \& Freischlag, 2010; Twycross, 2002; Undre, Sevdalis, Healey, Darzi, \& Vincent, 2006; Xyrichis \& Lowton, 2008). As a result, a parallel interest has arisen in studing these changes as they might affect undergraduate education (Dumont, Brière, Morin, Houle, \& Iloko-Fundi, 2010).

The Faculty of Health Sciences (FSH) Linköping University, Sweden offers problem based curricula of medicine, nursing, occupational therapy, physiotherapy, biomedical laboratory science, medical biology and speech and language pathology. An interprofessional training ward (IPTW) was implemented 1996 (Wahlström, Sanden, \& Hammar, 1997) in order to help undergraduate students become proficient in teamwork. Reports on early experiences with IPTW at the University of Linköping and other Swedish universities have been published 
(Fallsberg \& Hammar, 2000; Fallsberg \& Wijma, 1999; Hylin, Nyholm, Mattiasson, \& Ponzer, 2007; Jacobsen \& Lindqvist, 2009; Wahlström \& Sandén,1998).

This paper reports on a student evaluation of the IPTW, which has now been operational for more than 10 years, thus providing insight into the long-term experiences of the ward. In particular, this study aimed to examine students' ${ }^{\prime}$ assessments of their progress in participating in interprofessional collaboration.

\section{Background}

Study context: All students at FHS complete a full-time interprofessional curriculum divided into three modules of seven, three and two weeks duration, respectively. Central features of this curriculum are shared, problem-based learning (PBL) in professionally mixed basegroups and the introduction of interprofessional learning during the first semester of the program_(Areskog, 1988; Foldevi, Sommansson, \& Trell, 1994; Hammar, Gustafsson, Svedin, Domeij, \& Heijl, 1997; Lidskog, 2008; Wilhelmsson et al., 2009). The curriculum has been continuously developed since 1986 . The backbone of this process is a group of teachers from all undergraduate programs with extensive experience of small group facilitation and interprofessional learning in the everyday pedagogical encounter (Wilhelmsson et al., 2009). They form a community of practice 'walking the talk' (Oandansan \& Reeves,2005).

The rotation at the IPTW is the final part of the interprofessional curriculum. There are three different IPTWs with geriatric or orthopedic specialties.

Setting: This study was conducted at the largest and first of the three interprofessional training wards set up at the University Hospital in Linköping. This ward is an independent part of a regular orthopaedic ward with eight beds. Patients are hospitalized for treatment for hip fractures and other orthopedic trauma; for general disorders of the locomotor system and other medical and social problems. The preoperative and postoperative care, treatment and 
rehabilitation are performed in cooperation by students from the programs of medicine, nursing, physiotherapy and occupational therapy.

About 20 students rotate every two weeks and form three teams, which cover the ward according to a fixed roster from 06.45 a.m. to 9.30 p.m. Each team is randomly composed and consists of 6-8 students (usually 1 occupational therapy, 3-4 nursing, 1 physiotherapy, 1-2 medical students). The crew of clinical supervisors includes one or two nurses present fulltime on the ward, and one physiotherapist, one occupational therapist, and two orthopaedic surgeons who are on the ward part-time. These professionals are legally responsible for treatment.

The pedagocial design involves daily team conferences and reflection sessions with students and tutors. A concluding seminar is held at the end of each two-week rotation, at this time, emergent problems related to professional and interprofessional conduct and the quality of care are investigated and discussed.

\section{Methods:}

Data collection and analysis: Over a period of 5 years 2004-2008 all 919 students on rotation on the ward were asked to complete an anonymous on the last day of the rotation.

In this questionnaire, the students were asked to asses to what extent the two weeks rotation had strengthened their insight; into the personal professional role, into the other students' professional roles, and into the value of team work within healthcare. A 10-point Likert scale was used $(1=$ not at all, $10=$ very much $)$.

Data were analyzed statistically with the use of SPSS. One-way analysis of variance (ANOVA) was used for comparisons between the different student groups. Post hoc test was done with the Tukey method. Pearson's correlation coefficients were calculated.

Ethics: Data stem from routine evaluation of the learning module. Participation in the written evaluation was voluntary. Ethical approval was not required because physical intervention, 
relation of dependency and other manipulations of the subjects were not involved (The Act Concerning the Ethical Review of Research Involving Humans (2003:460), 2003). Nevertheless, all data were gathered in accordance to safe ethical practice in terms of informed consent, anonymity and confidentiality.

\section{Results:}

Surveys were received from 841 students; 90 occupational therapy students, 99 physiotherapy students, 187 medical students and 465 nursing students. The response rate was $92 \%$. The results are summarized in Table 1.

In general, the students appreciated the effects of the rotation highly. The mean values varied between 6.8 and 8.5. The nurse students evaluated the effects on their own professional role significantly higher than the other student groups, who still rated highly. All students thought that their insight into the other students' professional roles had been strengthened to a high degree, without differences between the groups. The nurse students estimated that their insight into the value of teamwork had been strengthened to a significantly higher degree 8.5 $(8.3-8.7)($ mean(95\%confidence interval))than medical and physiotherapy students. Mean and 95\% confidence intervals $8.5(8.3-8.7)$ for nurses, $7.6(7.3-7.9)$ for medical students and 7.8 (7.4-8.2) for physiotherapy students. Occupational therapy students also had higher mean estimates than medical students.

There was a moderate correlation between the items. (Pearson's correlation coefficient: $r=$ $0.45-0.55)$

\section{Discussion}

Responses to the three questions showed that the students felt they had a higher level of insight concerning the students own professional role, into the professional roles of other students and into the importance of teamwork within the health care system, after taking part 
of the IPTW. This is in accordance with evaluations from other similar wards, albeit with shorter experience (Jacobsen \& Lindqvist, 2009; Ker et al., 2003; Ker, Mole, \& Bradley, 2003; Lindblom, Scheja, Torell, Åstrand, \& Felländer-Tsai, 2007; Ponzer et al., 2004; Reeves, Freeth, McCrorie, \& Perry, 2002). Macdonald et al.(2010) has noted the importance of knowing the professional role of others in the development of interprofessional competency. When the IPTW started in 1996, quantitative and qualitative evaluations were performed and showed encouraging results ( Fallsberg \& Wijma, 1999; Wahlström \& Sandén, 1998 ). The present results from 2004-2008 confirm our experiences from the whole 13-year period, even if the evaluation form is less extensive than the early evaluations from 1996 and 1998.

These positive results are supported by studies performed by the Swedish Medical Association, which conducted annual national independent surveys of registered medical doctors about two years after medical school graduation (Faresjö, Wilhelmsson, Pelling, Dahlgren, \& Hammar, 2007). The former Linköping students rated their ability to cooperate with other professions significantly higher than students from other medical schools.

The reason for the differences between Linköping and the other medical schools may be the compulsory interprofessional education in the curriculum. The students are comparatively advanced in interprofessional education when reaching the IPTW, understanding the aims and the mechanisms for such learning. The organisation of an IPTW may influence students' expectations and preferences, especially medical students who may attend parallel courses or have different schedules than students from other programs (Hylin et al., 2007; Jakobsen, Larsen, \& Hansen, 2010). The learning objectives at the IPTW in Linköping do not compete with clinical subspecialty subjects; students are allotted to either an orthopaedic or a geriatric ward.

Jacobsen et al (2010) found that a safe learning environment, status equality in an interprofessional context and expectations on students to take responsibility in decision- 
making and patient contact positively influenced medical students on an IPTW. In contrast to their other clinical learning experiences, the IPTW enabled them to make suggestions on treatment. Security and trust as a basis for learning and reshaping relations have been discussed by a number of researchers (Dahlgren,2010; Hofseth Almås, 2007; Martin, 2005; Wenger, 1998) and may be one explanation to our results.

Nursing students claim to gain insight in their own professional role to a slightly but significantly higher degree than the other professions. This may be due to the fact that nurses dominate in numbers and activities in the everyday life of a ward, whereas the other professionals have more of consultant roles and spend less time there. For many physiotherapy students and the majority of the occupational therapy students, the IPTW placement is their first acquaintance with a hospital ward. Medical students are accustomed to follow their preceptors to the variety of settings, a hospital ward is just one. A widespread expression describing the role of nurses in Sweden is 'spider in the web' relating to the continuity, proximity and coordination of information in relation to the patient (Lundh, Rosenhall, \& Törnkvist, 2006). Nursing students have many opportunities to show and test their skills in a familiar ward environment and develop problem-solving skills on the borders between intuition and insight (Dane \& Pratt, 2007). This may explain the high rating by these students.

The major limitation to this study is the evaluation instrument was not a validated instument. In addition, the instrument used in this study contained only three questions. As a result, care needs to be taken when generalizing the results from empirical work to other settings. 


\section{Conclusions}

"Rubbing shoulders" during a fortnight offers numerous opportunities for informal as well as organized exchange of views. An urge among the students to explain and show how "their" professional practice is relevant is inherent in many teams. This is reciprocal; while explaining to the other students, the student discovers the distinct features of her or his own profession.

The possibility for the students to follow patients through the entire course of care after admittance, for example after a fracture, subsequent operation and post-operative care and rehabilitation offers many learning opportunities. Students gain insight into all kinds of problems that patients encounter in a surgical operation and rehabilitation. The contacts that must be taken with primary care and municipal services also become clarified. Thus, not only individual medical or rehabilitation problems are addressed, but also system-level issues and social aspects of health care. A major advantage for the students' learning is that neither the patients, their medical records nor other information are specially arranged. In this manner, students acquire images of how complicated it sometimes is to establish a holistic view of the patient and, in the process, learn about the challenges of being part of an interprofessional team.

Further research should be focused on whether students' subjective views on their interprofessional education corresponds to later professional encounters with patients and positive effects on treatment.

The lack of such studies may indicate the complexity of studying long-term effects of interprofessional education (Reeves et al., 2010).

Health care is a complicated system based on professionalism, cooperation, empathy and devotion. We advocate that interprofessional training of students from all professions should be a part of their education as a worthwhile preparation for their future professional work. An 
IPTW rotation is an example of a community of practice that offers insight to the advantages of interprofessional collaboration. 
Table 1. Student ratings on items. ANOVA least squares means and $95 \%$ confidence intervals. For each item, significance level for test of mean group differences.

\begin{tabular}{|c|c|c|c|c|}
\hline \multirow[b]{2}{*}{ Question } & \multicolumn{4}{|c|}{ Profession } \\
\hline & $\begin{array}{c}\text { Occupational } \\
\text { Therapy (OT) } \\
\text { N=90 }\end{array}$ & $\begin{array}{l}\text { Medicine (M) } \\
\quad \mathrm{N}=187\end{array}$ & $\begin{array}{c}\text { Nursing }(\mathrm{N}) \\
\mathrm{N}=465\end{array}$ & $\begin{array}{c}\text { Physiotherapy } \\
\text { (PT) } \\
\mathrm{N}=99\end{array}$ \\
\hline \multirow{3}{*}{$\begin{array}{l}\text { 1.... my own } \\
\text { professional role.. }\end{array}$} & 7.3 & 7.2 & 8.2 & 6.8 \\
\hline & $(6.9-7.7)$ & $(6.9-7.5)$ & $(8.1-8.4)$ & $(6.4-7.3)$ \\
\hline & $* * *<\mathrm{N}$ & $* * *<\mathrm{N}$ & $\begin{array}{r}* * *>\mathrm{OT}, \mathrm{M}, \\
\mathrm{PT}\end{array}$ & $* * *<\mathrm{N}$ \\
\hline \multirow{2}{*}{$\begin{array}{l}\text { 2. ...other } \\
\text { professionals... }\end{array}$} & 7.7 & 7.6 & 7.9 & 7.9 \\
\hline & $(7.4-8.1)$ & $(7.4-7.9)$ & $(7.8-8.1)$ & $(7.6-8.2)$ \\
\hline \multirow{4}{*}{ 3. ...teamwork... } & 8.4 & 7.6 & 8.5 & 7.8 \\
\hline & $(8.1-8.7)$ & $(7.3-7.9)$ & $(8.3-8.7)$ & $(7.4-8.2)$ \\
\hline & $* *>\mathrm{M}$ & $* *<\mathrm{OT}$ & $* * *>\mathrm{M}$ & $* *<\mathrm{N}$ \\
\hline & & $* * *<\mathrm{N}$ & $* *>\mathrm{PT}$ & \\
\hline \multicolumn{5}{|c|}{$* * p<.01, * * * p<.001$} \\
\hline
\end{tabular}

Question 1: This two-week rotation has strengthened my insight into my own professional role. Question 2: This two-week rotation has strengthened my insight into the roles of other health care professionals.

Question 3: This two-week rotation has strengthened my insight into the value of teamwork. 
References

1. The Act Concerning the Ethical Review of Research Involving Humans (2003:460), (2003).

2. Areskog, N. H. (1988). The need for multiprofessional health education in undergraduate studies. Medical Education, 22(4), 251-252.

3. Baxter, S. K., \& Brumfitt, S. M. (2008). Once a week is not enough: Evaluating current measures of teamworking in stroke. Journal of Evaluation in Clinical Practice, 14(2), 241-247.

4. Berlin, J. M., \& Carlström, E. D. (2008). The 20-minute team - a critical case study from the emergency room. Journal of Evaluation in Clinical Practice, 14(4), 569-576.

5. Bleakley, A., \& Bligh, J. (2008). Students learning from patients: Let's get real in medical education. Advances in Health Sciences Education : Theory and Practice, 13(1), 89-107.

6. Burke, C. S., Salas, E., Wilson-Donnelly, K., \& Priest, H. (2004). How to turn a team of experts into an expert medical team: Guidance from the aviation and military communities. Quality and Safety in Health Care, 13(SUPPL. 1), i96-i104.

7. Dahlgren, L. O. (2010). Interprofessional learning as a means of enhancing professional competence. Zeitschrift Für Evidenz, Fortbildung Und Qualität Im Gesundheitswesen, 104(1), 5-9.

8. Dane, E., \& Pratt, M. G. (2007). Exploring intuition and its role in managerial decision making. Academy of Management Review, 32(1), 33-54.

9. Dumont, S., Brière, N., Morin, D., Houle, N., \& Iloko-Fundi, M. (2010). Implementing an interfaculty series of courses on interprofessional collaboration in prelicensure health science curriculums. Education for Health, 23(1)

10. Fallsberg, M. B., \& Hammar, M. (2000). Strategies and focus at an integrated, interprofessional training ward. Journal of Interprofessional Care, 14(4), 337-350.

11. Fallsberg, M. B., \& Wijma, K. (1999). Student attitudes towards the goals of an interprofessional training ward. Medical Teacher, 21(6), 576-581.

12. Faresjö, T., Wilhelmsson, M., Pelling, S., Dahlgren, L. -., \& Hammar, M. (2007). Does interprofessional education jeopardize medical skills? Journal of Interprofessional Care, 21(5), 573-576.

13. Foldevi, M., Sommansson, G., \& Trell, E. (1994). Problem-based medical education in general practice: Experience from linkoping, sweden. The British Journal of General Practice : The Journal of the Royal College of General Practitioners, 44(387), 473-476.

14. Hammar, M., Gustafsson, P. A., Svedin, C. G., Domeij, D., \& Heijl, A. (1997). Personal and professional development in the training of communication and leadership in undergraduate medical education. Education for Health, 10(1), 57-68.

15. Harris, M., Chan, B., Daniel, C., Wan, Q., Zwar, N., \& Davies, G. (2010). Development and early experience from an intervention to facilitate teamwork between general practices and allied health providers: The team-link study. $B M C$ Health Services Research, 10(1), 104.

16. Hofseth Almås, S. (2007) Interprofessional education: an analysis of the introduction of a common core in curricula for selected health professions. PhD thesis, University of Bergen, Bergen.

17. Hylin, U., Nyholm, H., Mattiasson, A., \& Ponzer, S. (2007). Interprofessional training in clinical practice on a training ward for healthcare students: A two-year follow-up. Journal of Interprofessional Care, 21(3), 277-288. 
18. Jacobsen, F., \& Lindqvist, S. (2009). A two-week stay in an interprofessional training unit changes students' attitudes to health professionals. Journal of Interprofessional Care, 23(3), 242-250.

19. Jakobsen, F., Larsen, K., \& Hansen, T. B. (2010). This is the closest I have come to being compared to a doctor: Views of medical students on clinical clerkship in an interprofessional training unit. Medical Teacher, 32(9), e399-e406.

20. Ker, J., Mole, L., \& Bradley, P. (2003). Early introduction to interprofessional learning: A simulated ward environment. Medical Education, 37(3), 248-255.

21. Lidskog, M. (2008). Learning with, from and about each other: Interprofessional education on a training ward in municipal care for older persons. Örebro University, School of Health and Medical Sciences).

22. Lindblom, P., Scheja, M., Torell, E., Åstrand, P., \& Felländer-Tsai, L. (2007). Learning orthopaedics: Assessing medical students' experiences of interprofessional training in an orthopaedic clinical education ward. Journal of Interprofessional Care, 21(4), 413-423.

23. Lundh, L., Rosenhall, L., \& Törnkvist, L. (2006). Care of patients with chronic obstructive pulmonary disease in primary health care Blackwell Publishing Ltd.

24. Lupton, C., \& Khan, P. (1998). The role of health professionals in the UK child protection system: A literature review. Journal of Interprofessional Care, 12(2), 209221.

25. Macdonald, M B et al. (2010) Knowledge of the professional role of others: a key interprofessional competency. Nurse Education in Practice, 10(4), 238-242

26. Martin, J. (2005). Interprofessional education reframed by social practice theory. In $\mathrm{H}$. Colyer, M. Helme \& I. Jones (Eds.), The theory-practice relationship in interprofessional education

27. (http://www.health.ltsn.ac.uk/publications/occasionalpaper/occ7.pdf ed., pp. 49). London: The Higher Education Academy Health Sciences and Practice Network.

28. Oandasan, I., \& Reeves, S. (2005). Key elements for interprofessional education. part 1: The learner, the educator and the learning context. Journal of Interprofessional Care, 19, 21-38.

29. Patel, D. R., Pratt, H. D., \& Patel, N. D. (2008). Team processes and team care for children with developmental disabilities. Pediatric Clinics of North America, 55(6), 1375-1390.

30. Ponzer, S., Hylin, U., Kusoffsky, A., Lauffs, M., Lonka, K., Mattiasson, A. -., et al. (2004). Interprofessional training in the context of clinical practice: Goals and students' perceptions on clinical education wards. Medical Education, 38(7), 727-736.

31. Pronovost, P. J., \& Freischlag, J. A. (2010). Improving teamwork to reduce surgical mortality. JAMA : The Journal of the American Medical Association, 304(15), 17211722.

32. Reeves, S., Freeth, D., McCrorie, P., \& Perry, D. (2002). 'It teaches you what to expect in future...': Interprofessional learning on a training ward for medical, nursing, occupational therapy and physiotherapy students. Medical Education, 36(4), 337-344.

33. Reeves, S., Zwarenstein, M., Goldman, J., Barr, H., Freeth, D., Koppel, I., et al. (2010). The effectiveness of interprofessional education: Key findings from a new systematic review. Journal of Interprofessional Care, 24(3), 230-241.

34. Thistlethwaite, J., \& Moran, M. (2010). Learning outcomes for interprofessional education (IPE): Literature review and synthesis. Journal of Interprofessional Care, 24(5), 503-513.

35. Twycross, R. G. (2002). The challenge of palliative care. International Journal of Clinical Oncology, 7(4), 271-278. 
36. Undre, S., Sevdalis, N., Healey, A. N., Darzi, A., \& Vincent, C. A. (2006). Teamwork in the operating theatre: Cohesion or confusion? Journal of Evaluation in Clinical Practice, 12(2), 182-189.

37. Wahlström, O., \& Sandén, I. (1998). Multiprofessional training ward at Linköping university: Early experience. Education for Health, 11(2), 225-231.

38. Wahlström, O., Sanden, I., \& Hammar, M. (1997). Multiprofessional education in the medical curriculum. Medical Education, 31(6), 425-429.

39. Wenger, E. (1998). Communities of practice : Learning, meaning, and identity. Cambridge: Cambridge University Press.

40. Wilhelmsson, M., Pelling, S., Ludvigsson, J., Hammar, M., Dahlgren, L. O., \& Faresjö, T. (2009). Twenty years experiences of interprofessional education in Linkoping--ground-breaking and sustainable. Journal of Interprofessional Care, 23(2), 121-133.

41. Xyrichis, A., \& Lowton, K. (2008). What fosters or prevents interprofessional teamworking in primary and community care? A literature review. International Journal of Nursing Studies, 45, 140-153. 
